\title{
Seawater Upconing under a Pumping Horizontal Well in a Confined Coastal Aquifer
}

\author{
*Dongmin Sun and Perry Wong \\ Department of Physical and Applied Science, University of Houston, USA
}

Submission: February 24, 2017; Published: March 23, 2017

*Corresponding author: Dongmin Sun, Department of Physical and Applied Science, University of Houston, Clear Lake, Houston, Texas, USA, Email: sundon@uhcl.edu

\begin{abstract}
We have investigated the seawater Upconing due to a finite-length pumping horizontal well and derived an analytical solution of sharp fresh/sea interface based on the solution of Dagan \& Bear [1]. The results are compared with those of vertical wells. The Upconing profile exhibits three stages with time: an early slow increase stage, an intermediate rapid increase stage, and a late steady state stage. The sensitivity of the interface rise to the well length, the well location, the aquifer anisotropy, and the observation point location is analyzed. We have also investigated the critical condition of seawater Upconing based on Muskat [2] idea by relating fresh/sea water interface Upconing to drawdown. The critical condition which includes the critical rise and the critical time at a certain pumping rate depends on the well length, the initial interface location, the well location, and the pumping rate. The critical rise and the critical time are coupled together at any given pumping rate. The critical rise has an inversely linear relationship with the pumping rate and the initial interface location, respectively. The critical rise is more sensitive to a shorter well, while the critical time continuously increases with the well length. In real field applications, installing long wells as shallow as possible is always desirable for sustaining long periods of pumping with significant rates.
\end{abstract}

Keywords: Horizontal well; Seawater Upconing; Sharp interface; Critical rise; Critical time

\section{Introduction}

Coastal margins are one of the nation's greatest natural resources and economic assets. Due to increasing concentration of human settlements and economic activities in the coastal margins, it is critical to find better technologies of managing the coastal groundwater resources. Coastal aquifers always have saline water underneath the freshwater. This phenomenon substantially limits the groundwater pumping rates using traditional vertical wells because of the Upconing of the fresh/ sea water interfaces and the potential of seawater intrusion e.g. [1-7]. A horizontal well often has a much longer screen length than a vertical well, thus can intercept a significant amount of freshwater flow in a shallow coastal aquifer; meanwhile, a horizontal well distributes its pumping rate over a much longer screen length than a vertical well, thus generates much less Upconing of the fresh/sea water interface and has less chance to be invaded by the underneath saline water. Therefore, a horizontal well might be a better means for coastal aquifer development. Horizontal wells have been widely used in the petroleum industry in the past two decades [8-14]. They have been applied to environmental geology and hydrogeology since the pioneering work of collecting wells [15-31]

The analyses of Upconing phenomenon have been classified into two groups depending on the assumptions made regarding the interface of freshwater and seawater. One is sharp interface model, the other is transition zone model. The sharp interface model considers freshwater and seawater as immiscible fluids, ignores the mixing zone of these two fluids e.g. $[3,1,32,5,6]$ [3337]. This model is valid if mixing zone between the two fluids is relatively small compared with the thickness of the aquifer. The transition zone model considers the two fluids as miscible fluids, and a mixing zone exists at the boundary where these two fluids are in contact e.g. [38-45]. The basis of the most initial works of freshwater and saline water studies, especially the sharp interface model is Ghyben- Herzerg model $[46,47]$. Following the Ghyben-Herzerg model, extensive studies have been carried out e.g. [35,36] [48-55].

Two methods are widely used among previous sharpinterface studies. The first method is developed by Muskat [2] based on the Ghyben-Herzerg model, and the second method is devised by Dagan \& Bear [1], hereinafter called DB model based the small perturbation of the free interface. Muskat's model is capable of calculating the critical rise of the interface while the DB model can find the interface profile.

Most of studies related to seawater intrusion refer to vertical wells e.g. $[1,32,33,51,56,57]$. Only a few investigations are about the Upconing under infinitely-long horizontal wells [58-61]. 
Zhang and Hocking $[59,60]$ used boundary integral equation method to find the interface for different pumping rates of point sinks, and used hodograph method to obtain the shape of the interface for an infinitely long line-sink to solve the critical rate problem. Butler and Jiang [58] considered the effect of gravity to study the movement of the water-oil interface toward a horizontal well.

To the knowledge of the authors, seawater Upconing under a finite-length horizontal well during transient flow condition has not been studied yet. This article has two primary purposes. The first is to investigate the Upconing profile under a finite-length horizontal well at different times of pumping. The second is to derive the critical pumping time and the critical rise at any given pumping rate. The results are compared with previous vertical well solutions. The sensitivity of Upconing to the well length, the initial interface, and the well location has been investigated. This research is particularly useful for guiding the coastal aquifer development.

Seawater Upconing Profile under a Horizontal-Well in a Thick Aquifer

\section{Analytical Formulation}

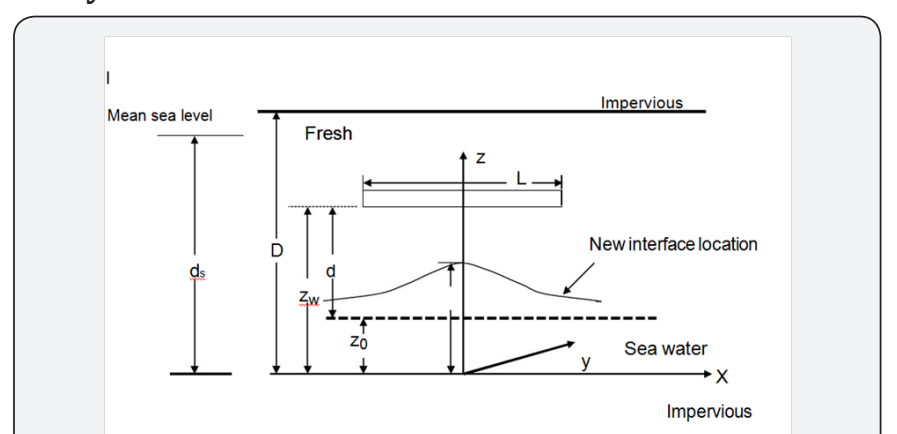

Figure 1: A schematic cross-section diagram of a pumping finite-length horizontal well above a fresh/sea water interface.

Figure 1 is a schematic diagram of a finite-length pumping horizontal well above a fresh/sea water interface. The coordinate system is set up in such a way that the origin is at the lower boundary of the aquifer, the $x$ - and $y$ - axes are along the horizontal directions and the z-axis is along the upward vertical direction. The horizontal well is positioned along the $\mathrm{x}$-axis with its center at $\left(0,0, z_{w}\right)$, where $z_{w}$ is the distance from the horizontal well to the lower aquifer boundary. The length of the well is $\mathrm{L}_{\mathrm{z}} \mathrm{z}_{0}$ is the distance from the pre-pumping initial horizontal interface to the lower boundary, and $d$ is the distance from the horizontal well to the initial interface. The upper and lower aquifer boundaries are impermeable (Figure 1).

In consistent with previous studies of Dagan \& Bear [1], we adopt the following assumptions in this investigation:

a. The medium is homogeneous, horizontally isotropic but vertically anisotropic. b. The fresh/sea water mixing zone has a negligible width (the so-called sharp interface).

c. The regional flow is not considered.

d. The upper and lower aquifer boundaries are far from the well's intake point and the fresh/sea water interface (the socalled thick aquifer in Dagan and Bear's paper).

The sharp interface treatment is a mathematical simplification of the problem since the focus of this article is to obtain some analytical solutions of the problem to gain physical insights. Dagan \& Bear [1], the so-called DB model, has derived an equation describing the Upconing of the interface as a function of time and distance from a pumping point in a thick aquifer. Expressed in the notation of this study, the DB model gives:

$$
Z(r, t)=\frac{Q}{2 \pi(\Delta \gamma / \gamma) K_{x} d}\left[\frac{1}{\left(1+R^{\prime 2}\right)^{\frac{1}{2}}}-\frac{1}{\left[\left(1+\gamma^{\prime}\right)^{2}+R^{\prime 2}\right]^{\frac{1}{2}}}\right],
$$

Where $\mathrm{R}$ and $\gamma$ are respectively the dimensionless distance and the time given by:

$$
\begin{aligned}
& R^{\prime}=\frac{r}{d}\left(\frac{K_{z}}{K_{x}}\right)^{\frac{1}{2}}, \\
& \gamma^{\prime}=\frac{(\Delta \gamma / \gamma) K_{z}}{2 n d} t,
\end{aligned}
$$

where $\mathrm{Z}$ is the rise of interface above the initial position, $\mathrm{Q}$ is the pumping rate of the well, $\gamma$ is the specific density of freshwater, $\Delta \gamma / \gamma$ is the dimensionless density difference between the two fluids, $d$ is the distance between the well's intake point and the initial interface, $r$ is the radial distance from the well, $n$ is the aquifer porosity, $\mathrm{K}_{\mathrm{x}}$ and $\mathrm{K}_{\mathrm{z}}$ are the horizontal and vertical hydraulic conductivities, respectively, and $\mathrm{t}$ is the pumping time.

We must emphasize that it is assumed that the aquifer is so thick that the upper and lower boundaries will not affect the pumping in using Eq. (1). This assumption is the precondition to achieve a possible stable profile of Upconing when time becomes very large. If the aquifer thickness is limited, the aquifer boundaries will greatly affect the rise of the Upconing and it will not be possible to achieve a stable Upconing profile, even with a small pumping rate. That is because drawdown at a point near the sink will continuously increase with time and steadystate flow is not possible near a sink point in a finite-thickness confined aquifer. If the thick aquifer assumption cannot be satisfied, Eq. (1) is at most an approximation of calculating the rise of Upconing before reaching the critical condition. A rigorous theoretical investigation considering the finite-thickness aquifer could be challenging. In this part, we will keep using the thick aquifer assumption in order to use Eq. (1).

The DB model deals with transient flow and will serve as the starting point of this study. The interface Upconing due to a pumping horizontal well can be derived by an integration of the point-sink solution along the horizontal well axis. For any point at the initial interface $(x, y)$, the rise of interface is 


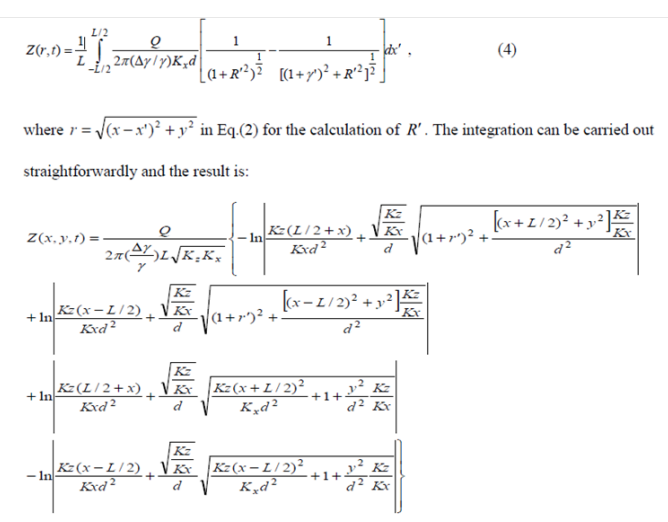

\section{Comparison of Upconing Profiles of Vertical and Horizontal Wells in a Thick Aquifer}

Eq. (5) is employed to analyze the Upconing profile under a pumping horizontal well. (Figure $2 \mathrm{~A}$ ) is a three dimensional view of the Upconing profile after pumping the horizontal well for $t=105 s=1.16$ days. The following parameters were used in this Figure: $\mathrm{d}=10 \mathrm{~m}, \mathrm{~L}=40 \mathrm{~m}, \mathrm{Kx}=\mathrm{Kz}=0.0001 \mathrm{~m} / \mathrm{s}, \mathrm{n}=0.1$, and $\mathrm{Q}=0.01 \mathrm{~m} 3 / \mathrm{sec}$. A three-dimensional Upconing profile due to a vertical pumping well is plotted in (Figure 2B) based on Eq. (1). We should point out that this vertical well only withdraws water from a point that is at the same vertical location as the horizontal well. For the sake of comparison, we use exactly the same aquifer parameters, initial interface, and pumping rate as those used in (Figure 2).

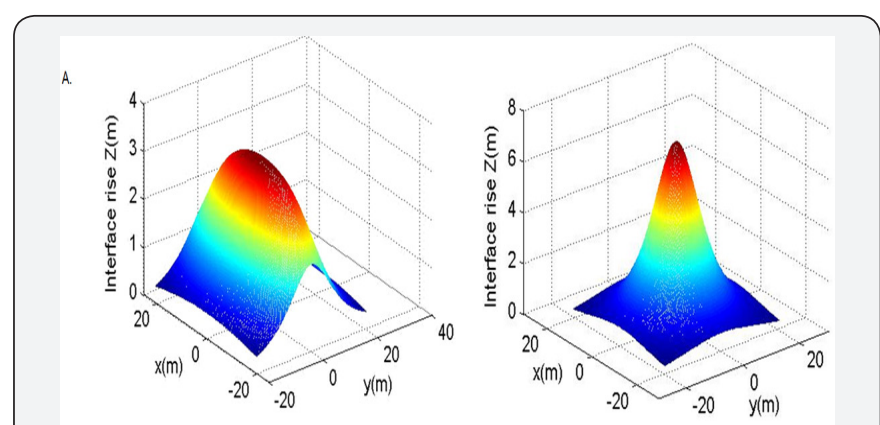

Figure 2: Three dimensional upconing profiles at $x=y=0, L=$ $40 \mathrm{~m}, \mathrm{~d}=10 \mathrm{~m}$, at 1.16 days. A) horizontal- well; B) vertical-well.

As expected, (Figure 2A) shows a symmetric profile in respect to the $y$-axis, and the largest Upconing is at point $\mathrm{x}=\mathrm{y}=0$. At time $t=105 \mathrm{~s}=1.16$ days, the maximal rise of interface is $3.31 \mathrm{~m}$ under a pumping horizontal well. In contrast, the highest rise of interface under a vertical well is $7.07 \mathrm{~m}$, which is more than twice of that of the horizontal well. This is understandable because the horizontal well distributes its pumping stress over a great lateral length, but a vertical well concentrates its pumping stress over a small localized volume. In fact, hydro geologists have recognized the importance of using a series of laterally distributed smallrate vertical wells instead of a single large-rate vertical well to pump coastal aquifers to prevent seawater Upconing a long time ago $[1,33,62]$. The study here moves one step further by replacing the series of vertical wells by a single horizontal well to reduce the seawater Upconing.
Figure 3A shows the rise of interface versus time under both vertical and horizontal wells at point $\mathrm{x}=\mathrm{y}=0$ in a semi-log paper. It is interesting to observe a three stage interface rise with time. At early time, the interface rise is small and the rate of rise is slow; from time between 103 to $6 \times 107$ seconds, there is a rapid interface rising; when time gets further longer, the interface almost reaches a steady-state condition. The three stage interface rise can be explained in the following. When the pumping starts, it takes some time (often quite short) for the pumping effect to reach the fresh/sea water interface, depending on the pumping rate and the distance to the interface, among other hydraulic properties. During this early stage, the fresh/sea water interface will not be affected. When the pumping effect propagates to the fresh/sea water interface, the interface will start to rise, first rapidly, then gradually slow down until reach a steady-state, this is the second stage. When the time is long enough, stead-state is reached, that is the third stage.

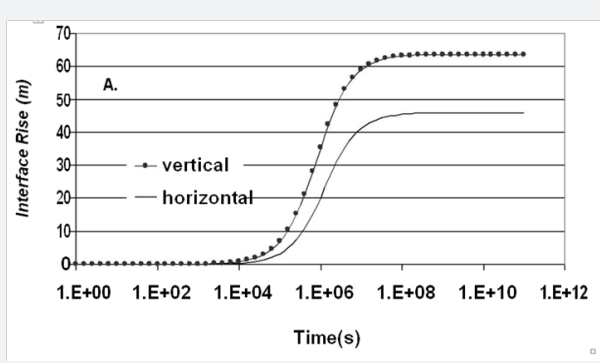

Figure 3:A) The interface rises versus time for horizontal and vertical wells; B) The ratio of the interface rise of a vertical well over that of a horizontal well.

Another interesting result shown in (Figure 3B) is that the ratio of interface rise under a vertical versus horizontal well is almost constant at the early time (before 103 seconds), while this ratio decreases during $3 \times 104$ to $2 \times 107$ seconds, and it is constant at 1.39 after $2 \times 107$ seconds. The ratio of 1.39 at the large time can be validated by comparing the steady-state simplification of Eqs. (1) and (5). When time goes to infinity, the second term in Eq. (1) goes to zero; whereas the first and second terms in Eq. (5) cancel each other. Given the parameters of $\mathrm{L}=40 \mathrm{~m}$ and $\mathrm{d}=10 \mathrm{~m}$, it can be easily proven that the ratio of rises calculated by Eq. (1) and (5) is approximately 1.39 after a few steps of mathematical manipulations (Figure 3).

\section{Physical Analysis of Interface Rise under a Horizontal Well}

As shown in Eq. (5), the interface rise under a pumping horizontal well is controlled by several parameters including the observation location, the well location, the well length and the aquifer anisotropy. It is important to find out the response of Upconing to the variation of those parameters. The same parameters as that in section 2.2 were also used here.

\section{Well location}

Figures $4 \mathrm{~A} \& 4 \mathrm{~B}$ show the interface rises at time $\mathrm{t}=105 \mathrm{~s}$ as functions of well locations for three observation points at the 
interface with $x=y=0, x=y=20 m, x=y=30 m$, where $x=y=0$ is the point directly below the center of the horizontal well. This figure shows a few interesting aspects. First, for the point directly below the center of the well, the interface rise is somewhat inversely proportional to $d$, reflected by the rapid decrease when the well is close to the interface, and then the asymptotic approach to zero when the well is away from the interface. This result is directly reflected in Eq. (4) which shows that Z is approximately inversely proportional to $\mathrm{d}$ if excluding the negligible contribution of $\gamma$ (Figure 4).

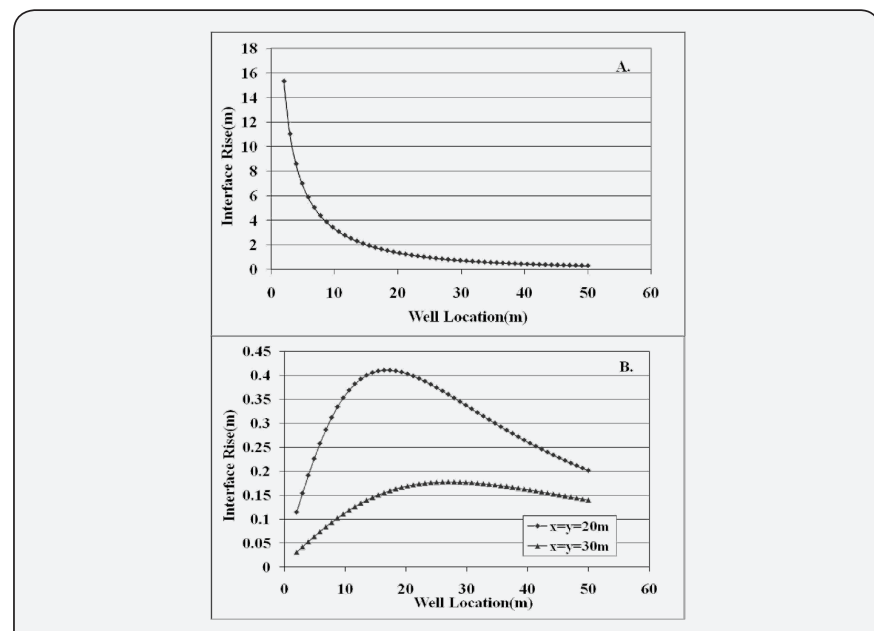

Figure 4: A) Effect of the well location on the interface rise at an observation point directly below the well center $(x=y=0 m) ; B)$ Effect of the well location on the interface rise at two off-center observation points $x=y=20 m$, and $30 \mathrm{~m}$.

Second, for an observation point at the interface that is not directly below the well center, the interface rise depends on the interplay of the well location d, denoted as factor 1 , and the horizontal distance between the observation point and the well center, denoted as factor 2 . When the horizontal well is close to the interface (small value of d), its influence upon the Upconing mostly concentrates on a local area below the well. When d increases, the interface rise tends to decrease. However, the influence area of the pumping also augments and reaches far, causing the increase of interface rises at points not directly below the well center. For example, at an off-center point of $x=y=20 m$, when $d$ is sufficiently small, the factor 1 dominates over the factor 2 , thus one observes smaller interface rise at small $d$ in (Figure 4B); when d reaches a moderate value, the factor 2 dominates over the factor 1 , thus one observes a maximal rise; when $\mathrm{d}$ further increases, the factor 1 dominates again, and the interface rise decreases. As a result, one observes a parabolic type of profile in (Figure 4B).

If the observational point is further away, for instance, at $\mathrm{x}=\mathrm{y}=30 \mathrm{~m}$, the well has to be further away from the initial interface to generate a large enough influence area to let the interface rise reaches its maximum at $d=26.96 \mathrm{~m}$ (Figure $4 \mathrm{~B}$ ). One also observes that the curve of interface rise over the well location d becomes flatter when the horizontal distance from the observational point to the well center becomes greater. The maximal Upconing is reached when the distance from the well to the initial interface is slightly smaller than the horizontal distance from the observation point to the well (Figure 4B).

\section{Well length}

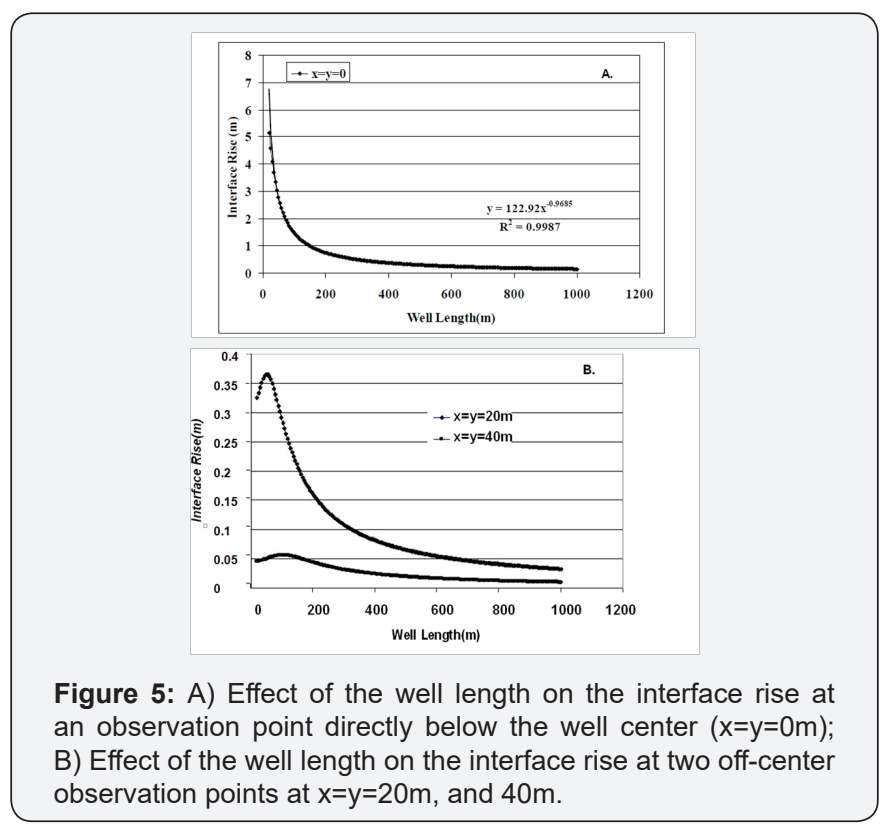

Figures 5A \& 5B show the relationship of interface rise with the well length at different monitoring points at the interface. For a point directly below the well center, $x=y=0$, the function of the interface rise $\mathrm{Z}$, versus the well length $\mathrm{L}$, can be approximated by a regression function

with a correlation coefficient $\mathrm{R}=0.999$. The interface rise decreases rapidly when the well length increases, and it gradually approaches zero when well is infinitely long. This is because the pumping rate has been distributed over a larger horizontal distance for a longer well, thus the pumping strength per unit screen length becomes weaker, causing a smaller interface rise right below the well. Although Figures 4A \& 5A shows some similar trend, the rate of change in (Figure $4 \mathrm{~A}$ ) is faster than that in Figure 5A, indicating that the interface rise is more sensitive to the well location than to the well length for the point below the well center.

For observational points that are not directly below the well center, such as those at $\mathrm{x}=\mathrm{y}=20 \mathrm{~m}$ and $40 \mathrm{~m}$, the interface rises depend on the interplay of two controlling factors in a fashion similar to that discussed in section 2.3.1: the pumping strength (reflected by the pumping rate per unit length), and the influence area of the well. The interface rise reaches its maximum at a certain length of the well, as indicated in (Figure 5).

\section{Aquifer Anisotropy}

Figure 6 shows the dependency of the interface rise as a function of the anisotropy ratio $(\mathrm{Kz} / \mathrm{Kx})$ for a point directly below the well. From an isotropic case of $\mathrm{Kz} / \mathrm{Kx}=1$ down to an anisotropic case of $\mathrm{Kz} / \mathrm{Kx}=0.3$, the interface rise almost linearly 
decreases from 3.31 to 1.56 . However, when the anisotropic ratio further decreases, the decrease of interface rise becomes slightly steeper, until reaches zero when $\mathrm{Kz} / \mathrm{Kx}=0$.

\section{Analysis of Critical Condition of Seawater Upconing}

The study described above is based on the work of Dagan \& Bear [1]. Although Dagan \& Bear [1] claimed that the interface will be stable for upconed heights that do not exceed one third of the distance between the well bottom and the initial interface, they did not directly solve the critical rise problem rigorously. In addition, Dagan \& Bear [1] is for an infinitely thick aquifer and it might not be suitable for dealing with a finite-thickness aquifer. In this section, we directly solve the critical rise problem using Muskat [2] idea based on the Ghyben-Herzerg model. The limitation of this method is analyzed in the discussion.

\section{Critical Condition}

It is well-known that a stable interface profile is only possible under a certain critical condition beyond which seawater will flow into the well $[2,3,32-34,56,57,63-65]$. The critical condition includes the critical pumping rate, the critical pumping time, and the critical rise. In a transient flow problem, these three parameters are interdependent on each other. The critical pumping rate refers to the maximal pumping rate without any seawater extraction at a certain time. The critical rise is the maximal interface rise to maintain a stable interface profile, and the critical time refers to the time when the critical rise is reached at a given pumping rate. It is of great importance to study the critical condition for managing coastal aquifers.

The critical rise is often expressed in terms of the ratio of the interface rise over the distance between the well and the initial interface (d). The critical rise due to a pumping vertical well has been studied by several investigators such as Bear \& Dagan [3], Bower et al. [63], Haubold [32], Motz [64], Muskat [2], Sahni [33], Schmorak \& Mercado [34], and Wirojanagud \& Charbeneau [65]. To the best knowledge of the authors, the previous studies of the critical rise are for vertical wells, and often focus on steadystate problems $[63,32,33]$. The primary focus of this section is to investigate the transient critical rise problem under a pumping horizontal well.

\section{Physical Model}

Muskat [2] proposed an idea to acquire the critical rise for a two-fluid flow system. That idea states that at the critical condition, both the pressure and the pressure gradient across the fresh/sea water interface are continuous. This idea has been employed in the following studies such as Bower et al. [63], Glover [50], Haubold [32], Motz [64] and Sahni [33]. In this work, we will use this idea to study the horizontal well problem.

The assumptions used here are identical to those used in section 2.1 except that the aquifer thickness is not necessarily infinite. In addition, Muskat [2] assumed a small perturbation of the interface variation that did not change the hydraulic head distribution of freshwater zone. Bear et al. [66] pointed out that the Muskat's model was valid for less than $20 \%$ rise of the cone from the initial position of the interface to the bottom of a vertical pumping well. Haubold [32] applied an empirical factor 1.33 to extend the Muskat's model from $20 \%$ to $50 \%$ of distance from the initial position of the interface to the bottom of a vertical well. Given the same pumping rate, a short-screen vertical well generally has a much steeper interface rise profile near the well bottom than a long-screen horizontal well, as can be seen from (Figures 2A \& 2B). Therefore, the small perturbation assumption used by Muskat often results in less error with the use of a horizontal well, as compared to the use of a vertical well, given the same pumping rate. Nevertheless, when the interface rise is more than $50 \%$ of distance from the initial position of the interface to the well, greater error will be introduced with the use of such an assumption. Continuity of pressure at the interface before pumping results in (Figure 1),

$$
\left(h_{0}-z_{0}\right) \gamma_{f}=\left(d_{s}-z_{0}\right) \gamma_{s},
$$

where $\gamma \mathrm{f}$ and $\gamma \mathrm{s}$ are the specific weights of seawater and freshwater, respectively; h0 is the initial hydraulic head in the aquifer; ds is the depth of mean sea level to the lower aquifer boundary; and $\mathrm{z} 0$ is the initial fresh/sea water interface location in relative to the lower aquifer boundary.

\section{Equal pressure}

After the start of pumping, the hydraulic head in the aquifer is $\mathrm{h}=\mathrm{h} 0$-s, where $\mathrm{s}$ is the drawdown. Denoting as the distance from the new interface to the lower aquifer boundary, the pressure balance at the interface becomes

$\left(d_{s}-\Delta\right) \gamma_{s}=(h-\Delta) \gamma_{f}=\left(h_{0}-s(z, t)-\Delta\right) \gamma_{f}$.

It can be obtained from Equations (6) and (7) that

$$
\Delta=\frac{s}{\delta-1}+z_{0},
$$

where $s=\gamma_{s} / \gamma_{f}$ is the ratio of specific weight of seawater over that of freshwater.

\section{Equal Pressure Gradient}

At any vertical location $\mathrm{z}$ in the freshwater zone, the pressure after certain time of pumping pf, is

$$
p_{f}=\left(h_{0}-s-z\right) \gamma_{f} .
$$

If the point is located in the seawater zone, one has

$p_{s}=\left(d_{s}-z\right) \gamma_{s}$

Therefore, their pressure gradients are,

$\frac{\partial p_{f}}{\partial z}=-\left(1+\frac{\partial s}{\partial z}\right) \gamma_{f}$,

And

$\frac{g s}{g b^{2}}=-\lambda^{2}$. 
At the critical condition, the pressure gradients at the interface are continuous. This leads to

$$
\frac{\partial s}{\left.\partial z\right|_{z=S^{s}}}=\not{\alpha}-1
$$

Where $\Delta^{c}$ refers to the distance from the interface to the lower aquifer boundary at the critical condition.

\section{Application to Confined Aquifers}

We consider a problem of transient flow to a horizontal pumping well (Figure 6). Because the interface rise is largest at location $\mathrm{x}=\mathrm{y}=0$, thus this point is chosen to analyze the critical rises under different circumstances. From Eqs. (8) and (13) and with the knowledge of drawdown in the aquifer, one can obtain the critical position of the interface, , and the corresponding critical time, ct Eqs. (8) and (13) are written into the following dimensionless formats:

$$
\begin{aligned}
& \Delta_{D}^{s_{D}}=\alpha s_{D}\left(t_{D}^{c}, \Delta_{D}^{c}\right)+z_{0 D}, \\
& \frac{\hat{\alpha} s_{D}}{\partial z_{D}}\left(\Delta_{D}^{c}, t_{D}^{c}\right)=\frac{1}{\alpha},
\end{aligned}
$$

with the definition of the dimensionless terms:

$$
\Delta_{D}^{c}=\Delta^{c} / D, t_{D}^{c}=\left(k_{z} / S_{s} D^{2}\right) t^{c}, \alpha=\frac{Q}{2 \pi K_{x} D^{2}(\delta-1)},
$$

$$
s_{D}=\left(2 \pi k_{x} D / Q\right) s, z_{0 D}=z_{0} / D,
$$

thickness. For a confined aquifer the drawdown at the interface below the center of a pumping horizontal well $(x=y=0)$ was given by Zhan et al. [30]:

$$
\begin{aligned}
& \left.s_{D}\left(z_{D}, t_{D}\right)=\frac{\sqrt{\pi}}{L_{D}} \int_{0}^{t_{D}} \operatorname{erf}\left[\frac{\left(L_{D} / 2\right)}{2 \sqrt{\tau}}\right] 1+2 \sum_{n=1}^{\infty} \cos \left(n \pi z_{D}\right) \cos \left(n \pi z_{m D}\right) \exp \left(-n^{2} \pi^{2} \tau\right)\right] \frac{d \tau}{\sqrt{\tau}}, \\
& \text { where } t_{D}=\frac{K_{z}}{S_{s} D^{2}} t, \quad L_{D}=\frac{L}{D} \sqrt{\frac{K_{z}}{K_{x}}}, x_{D}=\frac{x}{D} \sqrt{\frac{K_{z}}{K_{x}}}, y_{D}=\frac{y}{D} \sqrt{\frac{K_{z}}{K_{x}}}, z_{D}=\frac{z}{D}, z_{w D}=\frac{z_{w}}{D} . \\
& \text { Eqs. (14) and (15) can be solved simultaneously for } \Delta_{D}^{c} \text { and } t_{D}^{c} \text {. To do this, letting } z_{D}=\Delta_{D} \\
& \text { in Eq. (16), where } \Delta_{D}=\Delta / D \text {, and substituting Eq. (16) into (14), results in the critical rise } \Delta_{D}^{c} \\
& \text { and the critical time } t_{D}^{c} \text { simultaneously. }
\end{aligned}
$$

\section{Discussion of the Critical Condition}

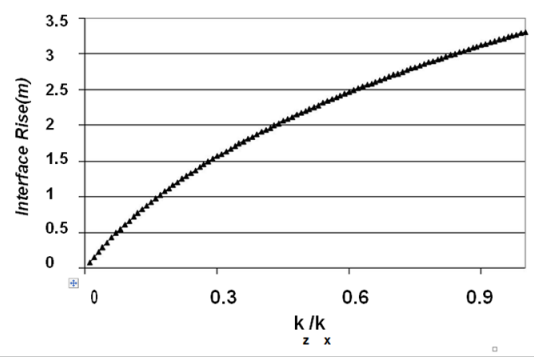

Figure 6: Effect of the aquifer anisotropy on the interface rise.

The critical condition is affected by several parameters such as the pumping rate, the well location, the initial interface location, and the well length. The dependency of the critical condition on those parameters is discussed below. The following default parameters are used in this discussion: horizontal well is located at the center of the aquifer ( $\mathrm{zwD}=0.5$ ), the dimensionless well length $L D=10$, and the dimensionless initial fresh/sea water interface z0D is 0.1 (Figure 6).

\section{Pumping Rate}

The effect of pumping rate is studied by changing the dimensionless pumping rate $\alpha$ from 1 to 3.0. Figures 7A \& 7B show the effect of pumping rate on the critical rise and the critical pumping time, respectively. Several observations are notable from these Figures. Under the transient flow condition in a confined aquifer, drawdown near the horizontal well will continuously increase with time, which will result in a continuously rising fresh/sea water interface until to a certain time (so-called critical time in our terminology) according to Eqs. (14) and (15). Thus, a stable interface is only possible within that critical time. Beyond the critical time, the interface becomes unstable and seawater intrudes the well. Therefore, a steadystate critical rise is not possible in a finite thickness confined aquifer. Under an assumption that the aquifer is infinitely thick, the critical time goes to infinity, and the steady-state critical time is achieved. Bear \& Dagan [3] have discussed such an infinitely thick aquifer under a pumping vertical well and have given estimations of the critical rises up to 0.5 (Figure 7).

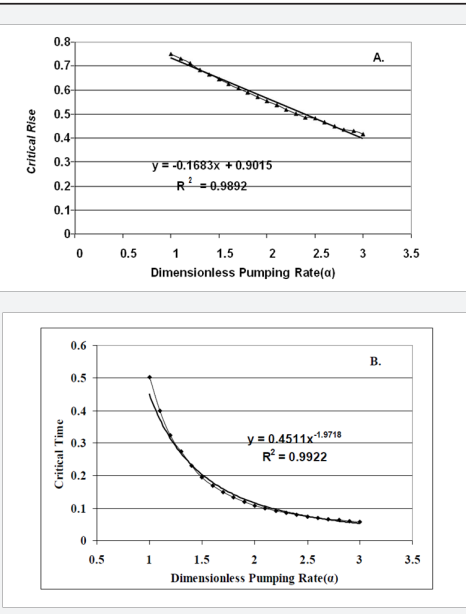

Figure 7: A) Effect of the dimensionless pumping rate on the critical rise; B) Effect of the dimensionless pumping rate on the critical time.

Under the transient flow condition, both the critical rise and the critical time decrease with pumping rate (Figures $7 \mathrm{~A}$ and 7B), but with different fashions. There is almost a perfect linear relationship between the critical rise and the pumping rate. The function of the critical rise defined as $F^{0}=\left(\Delta_{D}^{O}-z_{O D}\right) /\left(z_{W D}-z_{O D}\right)$, versus the dimensionless pumping rate,, can be approximated by a linear regression function with a correlation coefficient $\mathrm{R}=0.994$. The relationship of versus ? is nonlinear which can be closely approximated by a regression function $F^{c}-0.1683 \times \alpha+0.9015$ of with a correlation coefficient $\mathrm{R}=0.996$. The approximate linear relationship of $t_{D}^{\circ}$ in (Figure 7A) indicates that ${ }_{s_{D}\left(t_{D}^{\circ}, \Delta_{D}^{c}\right)}$ 
is insensitive to the change of $\Delta_{D}$ in Eq. (14). The nonlinear relationship of (Figure 7B) shows that the critical time is more sensitive to the change of $\alpha$ when $\alpha$ is smaller than 2.2 .

\section{Well Location}

Figures $8 \mathrm{~A}$ and $8 \mathrm{~B}$ show and as functions of zwD, respectively. Both and increase with zwD but respond with different trends. When zwD varies from 0.2 to 0.45 , the critical time is relatively insensitive to the well location change. When zwD varies from 0.5 to 0.9 , versus zwD fits into an approximately linear function. changes from 0.66 to 0.84 when zwD varies from 0.25 to 0.9 . Figures $8 \mathrm{~A}$ clearly show that the closer the well to the initial interface location, the smaller of the critical rise, and the shorter of the critical pumping time. The critical rise is more sensitive to the change of well location when the well is closer to the initial interface (Figure 8).

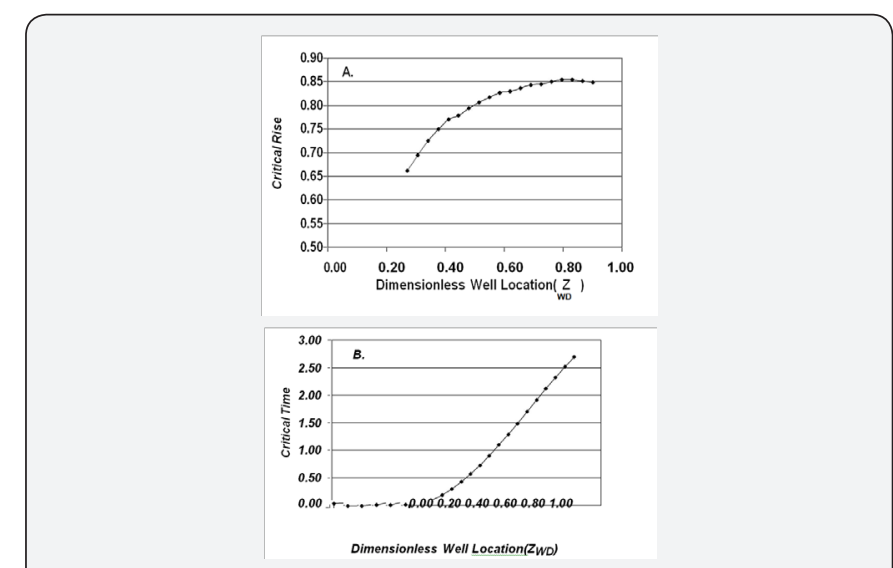

Figure 8: A) Effect of the well location on the critical rise; B) Effect of the well location on the critical time.

\section{Initial Fresh/Sea Water Interface}

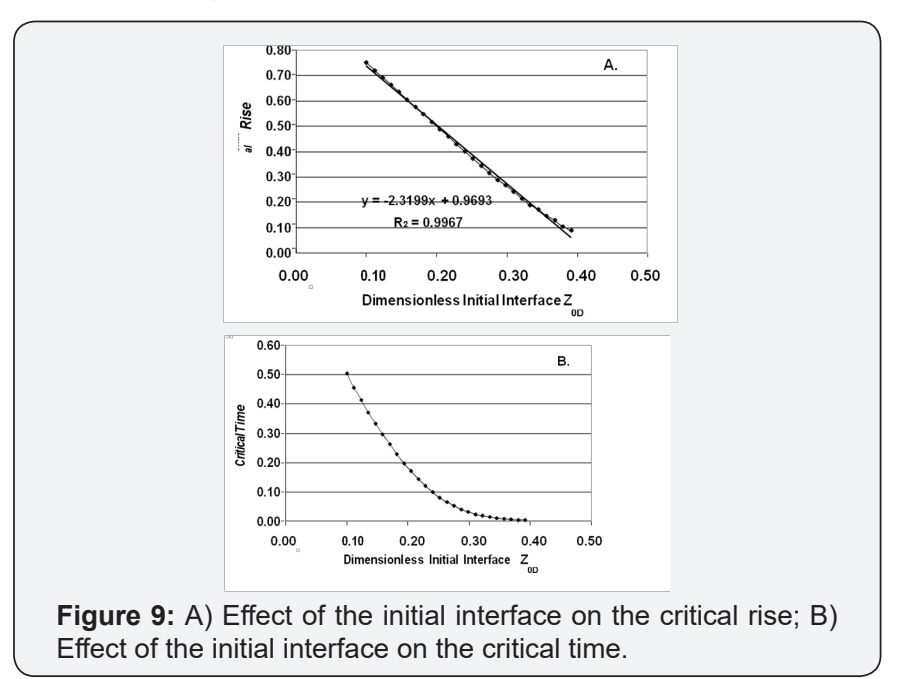

Figures 9A \& 9B show the effect of initial interface location. The critical rise is linearly dependent on the initial interface location, and this linear relationship can be approximated by a regression function with a correlation coefficient $\mathrm{R}=0.998$. The critical time also decreases with z0D when the initial interface is farther from the lower aquifer boundary. The case of z0D $=0.1$ corresponds to $=0.79$ and $=0.5$, respectively. When $\mathrm{z} 0 \mathrm{D}$ is at 0.3-0.4 which implies that the initial interface is very close to horizontal well $(\mathrm{zwD}=0.5)$, the system will reach the critical condition shortly after pumping $(=0.003$ ) with a small critical rise of 0.09 (Figure 9).

\section{Well Length}

To know the effect of well length on the critical rise and the critical time, and to choose an optimized well length to prevent seawater intrusion, the critical rise and the critical time are calculated as well length LD varies over a wide range from 1 to 180 . Figure $10 \mathrm{~A}$ shows that the critical rise is very sensitive to the well length when LD is relatively short. When LD changes from 1 to 20 , the critical rise increases substantially from 0.288 to 0.858 . When $\mathrm{LD}$ is longer than 20 , the critical rise becomes less sensitive to the well length and its value changes only slightly while well length gets longer. For example, when the well length changes from 50 to 100 , the corresponding critical rise only increases 0.015 . When LD is larger than 50 , the critical rise is nearly unity, implying that the interface is close to the horizontal well, but the interface profile could still remain stable. This conclusion has important practical application for preventing seawater intrusion. It means that when the horizontal well is sufficiently long ( $L D>50)$, one can maintain a stable interface profile even when the interface is close to the well. For practice of using horizontal well for water supply in coastal aquifers, this indicates that one can use a long horizontal well to withdraw significant amount of freshwater before the seawater intrudes the well. Such a scenario is hardly seen when using vertical wells in which the critical rises are unlikely above 0.3-0.6 [2,3,34,65] (Figure 10).

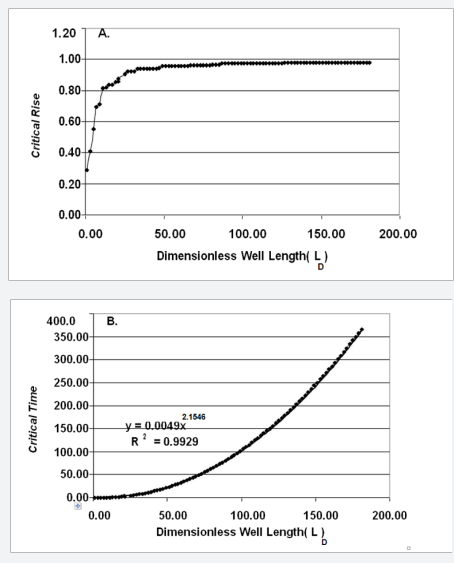

Figure 10: A) Effect of the well length on the critical rise; B) Effect of the well length on the critical time.

There is an almost perfect correlation between the well length and the critical time shown in (Figure 10), $t_{D}^{c}=0.0049 \times L_{D}{ }^{2.1546}$ with a correlation coefficient $\mathrm{R}=0.996$. When well gets longer, it takes longer time to reach the critical condition. This also implies that longer wells would be preferred for practice for pumping freshwater in coastal aquifers. 


\section{Discussion}

Several issues of this study deserve further discussion.

i. The three dimensional Upconing profile under a pumping horizontal well is acquired based on Dagan and Bear's model [1] of an infinite thick aquifer, therefore, the conclusion might not be applicable to thin coastal aquifers. This resulting profile is only valid if the interface rise is below one third of the distance from the well to the initial interface [67].

ii. Previous studies of critical condition using vertical wells often claimed that the critical rise was around 0.48 [2], or 0.5 [3], or 0.35 [65]. A maximum permitted pumping rate without seawater intrusion was then given by considering the critical rise [68]. However, the critical condition for a horizontal well pumping case in a confined aquifer is a dynamic process. One needs to consider aquifer and well properties, instead of simply giving a maximal pumping rate based on a critical rise value. This study showed that the critical rise and the critical time are coupled together at any given pumping rate in a transient flow problem. If the pumping rate is determined a priori, the critical rise will be reached at a certain critical time beyond which the interface profile becomes unstable. If the pumping period goes to infinity in a confined aquifer, the critical condition will inevitably be reached eventually, no matter how small the pumping rate is. A longer pumping time can be achieved at the expense of smaller pumping rate, while a larger pumping rate is only possible when pumping time is short to maintain a stable profile.

iii. The critical condition depends on the well location, the well length, the pumping rate, and the initial fresh/sea water initial interface, as analyzed above. How to balance the effects of these parameters and economic consideration is a challenge for the water management when a horizontal well is applied to a coastal aquifer. As shown in Figures 7A \& 9A, the critical rise has an inverse linear relationship with the pumping rate and the initial interface, respectively. However, the slope in (Figure 9A) is greater than that in (Figure 7A), indicating that the critical rise is more sensitive to the distance between the well and the initial interface than the pumping rate. If the initial fresh/sea water interface is low (close to the lower aquifer boundary), the interface could rise up to a position close to the well while is still stable. If the initial interface is high (far from the lower aquifer boundary), the critical rise tends to be small. Therefore, a long horizontal well is preferred to keep a sufficiently long critical time. In summary, a horizontal well with a longer well screen length with further distance from the initial interface is always desirable.

iv. The critical condition was investigated based on Muskat [2] model which assumed that the seawater was stagnant. Neglecting the dynamic process of response in the seawater zone could result in unrealistically large interface rise. For instance, the Ghyben- Herzerg relationship used by Muskat [2] deals with static condition which showed that one foot drop of freshwater would cause approximately 40 feet of rising of seawater. The realistic interface rise under transient, dynamic motion of both freshwater and seawater should be smaller than that predicted by the Ghyben- Herzerg relationship. It is generally accepted that the calculated critical condition tends to be accurate when the interface rise is less than $20 \%$ of the distance between the well and the initial interface [67]. The primary purpose of this study is for gaining the physical insights of interface Upconing under a pumping horizontal well. We are aware that the calculated critical time is short in a thin confined aquifer because of the usage of the Ghyben- Herzerg relationship. Therefore, it is not recommended to use the calculated critical time for precise prediction in real field applications. On the other hand, we are also aware that the pressure gradient Eq. (13) is almost independent of time after a short period of pumping, which is consistent with previous studies by Rosa \& Carvalho [69] and Zhan \& Cao [28]. In fact, Zhan \& Cao [28] have illustrated this issue in details and shown that the first spatial derivative of drawdown due to a pumping horizontal well in a confined aquifer is independent of time after entering the so-called pseudoradial flow stage. Therefore, the calculated critical rise, which is derived on the basis of continuity of pressure and pressure gradient, is likely to be more reliable than the calculated critical time in this study.

\section{Conclusion}

An analytical solution of three dimensional seawater Upconing due to a finite-length horizontal well is derived by integrating the point sink solution of Dagan \& Bear [1] along the horizontal well screen. This study assumes a sharp interface between the freshwater and the seawater, neglecting the transition zone between these two fluids. The resulting Upconing profile is compared with that of a vertical well using the same aquifer parameters. The Upconing profile exhibits three stages with time: an early slow increase stage, an intermediate rapid increase stage, and a late steady state stage. Given the same pumping rate and the distance from the well bottom to the initial interface, the interface rise at a fixed observation point is much smaller due to a horizontal well than to a vertical well.

The sensitivity of the interface rise to the well location, the well length, and the aquifer anisotropy has been thoroughly discussed. In general, the interface rise is very sensitive to the well location when the well is close to the initial interface for a point right below the well center. For an off- center point, the interface rise depends on the interplay of the well location and the horizontal distance from the observation point to the well. The maximal Upconing is reached when the distance from the well to the initial interface is slightly smaller than the horizontal distance from the observation point to the well. The interface rise is less sensitive to the well length than the well location. For a point right below the well center, the interface rise decreases when increasing the well length. If the well is not very long (Figure 5A), the interface rise is sensitive to the well length. Similar to the influence of the well location, the interface 
rise also depends on the interplay of the well length and the horizontal distance from the observation point to the well.

The critical rise and the critical time are studied by relating the interface rise to the drawdown and by employing Muskat [2] idea: pressure and pressure gradient are continuous across the sea/fresh water interface. They are coupled together at any given pumping rate in a transient flow problem. The critical rise depends on the initial interface location, the pumping rate, the well location, and the well length. The critical rise has an inversely linear relationship with pumping rate and the initial interface location, respectively. However, the critical rise is more sensitive to the distance between the well and the initial interface than the pumping rate. The critical pumping time decreases with the increasing pumping rate. The closer the well to the initial interface, the shorter of the critical time is. The critical condition is also controlled by the well screen length. The critical rise is sensitive to the well length when it is not long ( $L D<50$ in Figure 10A), and less sensitive when well gets longer (LD > 50 in Figure 10A), while the critical time continuously increases when well length gets longer. In real field applications, installing long wells as shallow as possible is always desirable for sustaining long periods of pumping with significant rates. The limitations of this study are originated from the assumptions used in Dagan \& Bear's [1] model in investigating the interface profile and the Muskat's [2] model in studying the critical condition.

\section{References}

1. Dagan G, Bear J (1968) Solving the problem of interface Upconing in a coastal aquifer by the method of small perturbations. J Hydraul Res 6(1): 15-44.

2. Muskat M (1982) The Flow of Homogeneous Fluids through Porous Media. International Human Resources Development Corporation, Boston, USA.

3. Bear J, Dagan G (1964) Some exact solutions of interface problems by means of the hodograph method. J Geophys Res. 69(2): 1563-1572.

4. Bear J, Cheng A HD, Sorek S, Ouazar D, Herrera I (1999) Seawater Intrusion in Coastal Aquifers: Concepts, Methods and Practices. Kluwer Academy, Norwell, Massachusetts, USA.

5. Henry HR (1959) Salt intrusion into freshwater aquifers. J Geophys Res 64: 1911-1919.

6. Henry HR (1964) Effects of dispersion on salt encroachment in coastal aquifers. US Geol Survey Water-Supply Paper 1613C: C70-C84.

7. Voss CI (1984) A finite element simulation model for saturatedunsaturated, fluid-density-dependent ground-water flow with energy transport or chemically-reactive singles-species solute transport. US Geol Surv Water Resour Invest 84-4369.

8. Daviau F, Mouronval G, Bourdarot G, Curutchet P (1988) Pressure analysis for horizontal-wells. SPE Formation Eval 3(4): 716-724.

9. Goode PA, Thambynayagam RKM (1987) Pressure drawdown and buildup analysis of horizontal wells in anisotropic media. SPE Formation Eval 2(4): 683-697.

10. Kuchuk FJ, Goode PA, Wilkinson DJ, Thambynayagam RKM (1991) Pressure transient behavior of horizontal wells with and without gas cap or aquifer. SPE Formation Eval 6(1): 86-94.
11. Ozkan E, Raghavan R, Joshi SD (1989) Horizontal well pressure analysis. SPE Formation Eval 4(4): 567-575.

12. Ozkan E, Raghavan R (1991) New solutions for well-test analysis problems: part 1-analytical considerations. SPE Formation Eval 6(3): 359-368.

13. Ozkan E, Raghavan R (1991) New solutions for well-test analysis problems: part 2-computational considerations and applications. SPE Formation Eval 6(3): 369-378.

14. Penmatcha VR, Arbabi S, Aziz K (1997) Effect of pressure drop in horizontal wells and optimum well length. In: Proceedings of the 1997 SPE Production Operation Symposium, Soc Pet Eng Oklahoma City, Oklahoma, USA.

15. Chen C, Wan J, Zhan H (2003) Theoretical and experimental studies of coupled seepage-pipe flow to a horizontal well. J Hydrol 281(1-2): 163-175.

16. Cleveland TG (1994) Recovery performance for vertical and horizontal wells using semianalytical simulation. Ground Water 32(1): 103-107.

17. Falta RW (1995) Analytical solutions for gas-flow due to gas injection and extraction from horizontal wells. Ground Water 33(2): 235-246.

18. Hantush MS, Papadopulos IS (1962) Flow of ground water to collector wells. J Hydraulic Div Proc Am Soc Civ Eng HY5 pp. 221-244.

19. Morgan JH (1992) Horizontal drilling applications of petroleum technologies for environmental purposes. Ground Water Monit Rev 12(3): 98-102.

20. Murdoch LC (1994) Transient analyses of an interceptor trench. Water rescour Res 30(11): 3023-3031.

21. Park E, Zhan H (2002) Hydraulics of a finite-diameter horizontal well with wellbore storage and skin effect in leaky aquifers. Adv Water Resour 25(4): 389-400.

22. Park E, Zhan H (2003) Hydraulics of horizontal well in fractured shallow aquifer systems. J Hydrol 281(1-2): 151-162.

23. Sawyer CS, Lieuallen Dulam KK (1998) Productivity comparison of horizontal and vertical ground water remediation well scenarios. ground water 36(1): 98-103.

24. Streward DR, Jin W (2001) Gaining and losing sections of horizontal wells. Water Resour Res. 37(11): 2677-2685.

25. Sun D, Zhan H (2006) Flow to a horizontal well in an aquifer-aquitard sys Tem. Journal of Hydrology 321(1-4): 364-376.

26. Tarshish M (1992) Combined mathematical model of flow in an aquifer-horizontal well system. Ground Water 30(6): 931-935.

27. Zhan H (1999) Analytical study of capture time to a horizontal well. J Hydrol 217(1-2): 46-54.

28. Zhan H, Cao J (2000) Analytical and semi-analytical solutions of horizontal well capture times under no-flow and constant -head boundaries. Adv Water Resour 23(8): 835-848.

29. Zhan H, Park E (2003) Hydraulics of horizontal wells in leaky aquifers. J Hydrol 281(1-2): 133-150.

30. Zhan H, Wang LV, Park E (2001) On the horizontal-well pumping tests in anisotropic confined aquifer. J Hydrol 252(1-4): 37-50.

31. Zhan H, Zlotnik VA (2002) Ground water flow to horizontal and slanted wells in unconfined aquifers. Water Resour Res 38(7): 1-11.

32. Haubold RG (1975) Approximation for steady interface beneath a well pumping fresh water overlying salt water. Ground Water 13(3): 254259.

33. Sahni BM (1973) Physics of brine coning beneath skimming wells. Ground water 11(1): 19-24. 
34. Schmorak S, Mercado A (1969) Upconing of fresh water-sea water interface below pumping wells, field study. Water Resour Res 5(6): 1290-1311.

35. Strack ODL (1976) A single-potential solution for regional interface problems in coastal aquifers. Water Resour Res 12(6): 1165-1174.

36. Strack ODL (1984) Three-dimensional streamlines in DupuitForchheimer models. Water Resour Res 20(7): 812-822.

37. Taylor JZ, Person M (1998) Capture zone delineations on island aquifer systems. Ground Water 36(5): 722-730.

38. Abarca E, Clement TP (2009) A novel approach for characterizing the mixing zone of a saltwater Wedge. Geophysical Research letters 36(6).

39. Diersch HJ (1988) Finite element modeling of recirculating density driven saltwater intrusion processes in groundwater. Adv Water Resour 11: 25-43.

40. Frind EO (1982) Simulation of long -term transient density-dependent transport in ground water. Adv Water Resour 5(2): 89-97.

41. Galeati G, Gambolati G, Neuman SP (1992) Coupled and partially coupled Eulerian-Lagrangian model of freshwater-saltwater mixing. Water Resour Res 28(1): 149-165.

42. Lu C, Kitanidis PK, Luo J (2009) Effects of kinetic mass transfer and transient flow conditions on widening mixing zones in coastal aquifers. Water Resour Res 45(12).

43. Volker R, Rushton K (1982) An assessment of the importance of some parameters for sea-water intrusion in aquifers and comparison of dispersive and sharp-interface modeling approaches. J Hydrol 56(34): 239-250.

44. Voss CI, Simmons CT, Robinson NI (2010) Three-dimensional benchmark for variable-density flow and transport simulation: matching semi-analytic stability modes for steady unstable convection in an inclined porous box. Hydrogeology Journal 18(1): 5-23.

45. Voss CI, Souza WR (1987) Variable density flow and solute transport simulation of regional aquifers containing a narrow freshwatersaltwater transition zone. Water Resour Res 23(10): 1851-1866.

46. Ghyben WB (1889) Notes on the probable results of the proposed well drilling near Amestrdam, K Inst Ingrs Tijdschr, The Hague, Netherlands, Europe, p. 21.

47. Herberg A (1901) Die wasserversorgung einiger Nordseebder, Z Gasbeleucht. Wasserversorg 44: 815-819, 45: 842-844.

48. Bakker M (2003) A Dupuit formulation for modeling seawater intrusion in regional aquifer systems. Water Resour Res 39(5).

49. Cheng AHD, Halhal D, Naji A, Ouazar D (2000) Pumping optimization in saltwater-intruded coastal aquifers. Water Resour Res 36(8): 21552165.

50. Glover RE (1959) The pattern of fresh- water flow in a coastal aquifer. J Geophys Res 64(4): 457-459.

51. Haitjema HM (1991) An analytic element model for transient axisymmetric interface flow. J Hydrol 129(1-4): 215-244.
52. Liu PLF, Cheng AHD, Liggett JA, Lee JH (1981) Boundary integral equation solutions of moving interface between two fluids in porous media. Water Resour Res 17(5): 1445-1452.

53. Mercer JW, Larson SP, Faust CR (1980) Simulation of salt water interface motion. Ground Water 18(4): 374-385.

54. Strack ODL (1995) A Dupuit -Forchheimer model for three dimensional flow with variable density. Water Resour Res 31(12): 3007-3017.

55. Chandler RL, McWhorter DB (1975) Upconing of the salt-water-freshwater interface beneath a pumping well. Ground Water 13(4): 354359.

56. Reilly TE, Goodman AS (1985) Quantitative analysis of saltwaterfreshwater relationships in groundwater systems- a historical perspective. J Hydrol 80(1-2): 125-160.

57. Reilly TE, Goodman AS (1987) Analysis of saltwater upcoming beneath a pumping well. J Hydrol 89(3-4): 169-204.

58. Butler RM, Jiang Q (1996) Effect of gravity on movement of wateroil interface for bottom water driving upwards to a horizontal well. Journal of Canadian Petroleum Technology 35(7): 47-56.

59. Zhang H, Hocking GC (1996) Withdrawal of layered fluid through a line sink in a porous medium. J Aust Math Soc B 38: 240-254.

60. Zhang H, Hocking GC (1997) Axisymmetric flow in an oil reservoir of finite depth caused by a point sink above an oil-water interface. J Eng Math 32(4): 365-376.

61. Zhang H, Hocking GC, Barry DA (1997) An analytical solution for critical withdrawal of layered fluid through a line sink in a porous medium. J Aust Math Soc B 39: 271-279.

62. Hantush MS (1964) Hydraulic of Wells. In: Chow VT, Advances in Hydroscience, Academic Press, New York, USA.

63. Bower JW, Motz LH, Durden DW (1999) Analytical solution for determining the critical condition of saltwater upconing in a leaky artesian aquifer. J Hydrol 221(1-2): 43-54.

64. Motz LH (1992) Salt-water upconing in an aquifer overlain by a leaky confining bed. Ground Water 30(2): 192-198.

65. Wirojanagud P, Charbeneau RJ (1985) Saltwater upconing in unconfined aquifers. J Hydraulic Engineering 111(3): 417-434.

66. Bear, J, Zaslavasky D, Irmay S (1968) Physical Principles of Water Percolation and Seepage, UNESCO, Paris, pp. 465.

67. Saeed M, Bruen M, Asghar MN (2002) A review of modeling approaches to simulate saline-upconing under skimming wells. Nordic Hydrology 33(2-3): 165-188.

68. Domenico PA, Schwartz FW (1998) Physical and Chemical Hydrogeology. John Wiley \& Sons, New York, USA.

69. Rosa AJ, Carvalho (1989) A mathematical model for pressure evaluation in an infinite-conductivity horizontal well. SPE Formation Eval 4(4): 559-566.

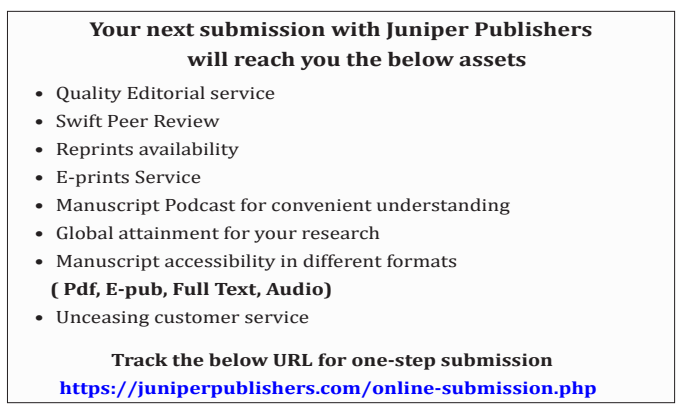

